\title{
Macrodystrophia lipomatosa
}

\author{
Jonathan R. Dillman • Peter J. Strouse
}

Received: 11 June 2009 /Revised: 24 June 2009 /Accepted: 10 July 2009/Published online: 27 August 2009

(C) Springer-Verlag 2009

A 5-year-old girl presented with left hand enlargement since birth. Visual inspection revealed left index and middle finger macrodactyly. Left hand radiographs demonstrated marked osseous and soft-tissue overgrowth of the second (index) and third (middle) digits (Figs. 1 and 2), consistent with macrodystrophia lipomatosa in a median nerve distribution. Areas of soft-tissue overgrowth appeared radiolucent, suggesting the presence of fat. The right hand was normal.

Macrodystrophia lipomatosa is a rare nonhereditary form of focal gigantism that is characterized by osseous and fibroadi-

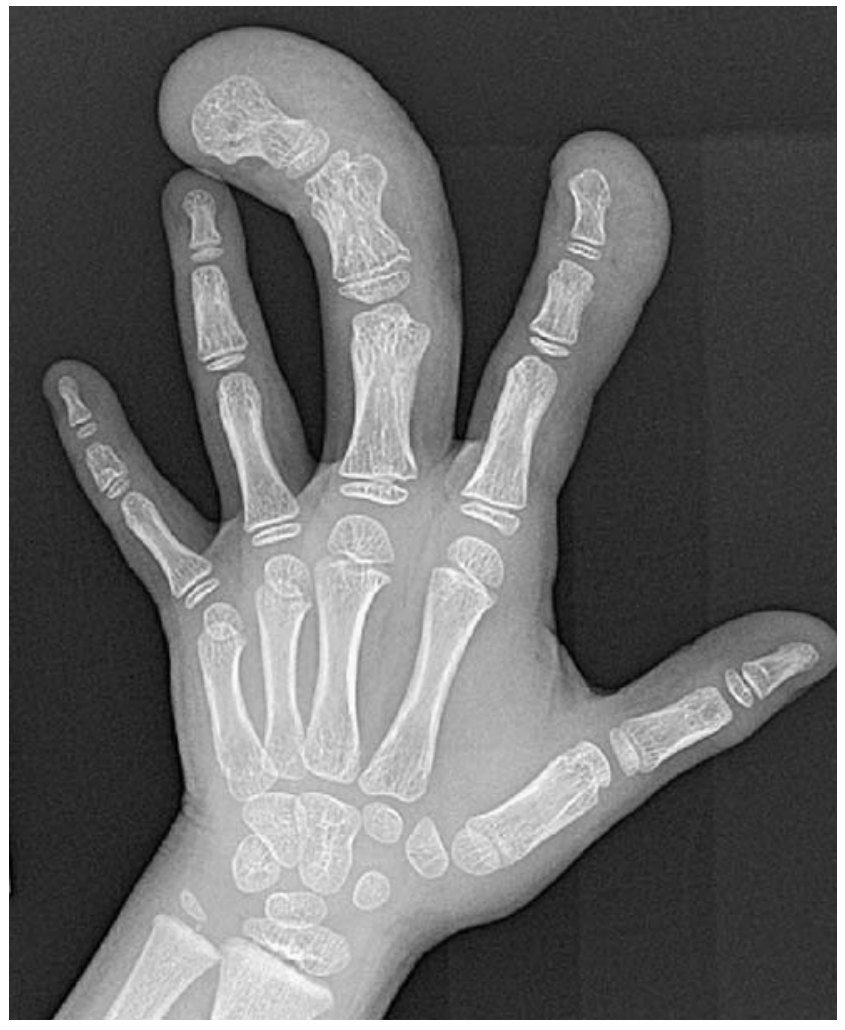

Fig. 1 Oblique radiograph, left hand

J. R. Dillman $(\bowtie) \cdot$ P. J. Strouse

Department of Radiology, Section of Pediatric Radiology,

University of Michigan Health System,

C. S. Mott Children's Hospital, F3503,

1500 E. Medical Center Drive,

Ann Arbor, MI 48109-5252, USA

e-mail: jonadill@med.umich.edu

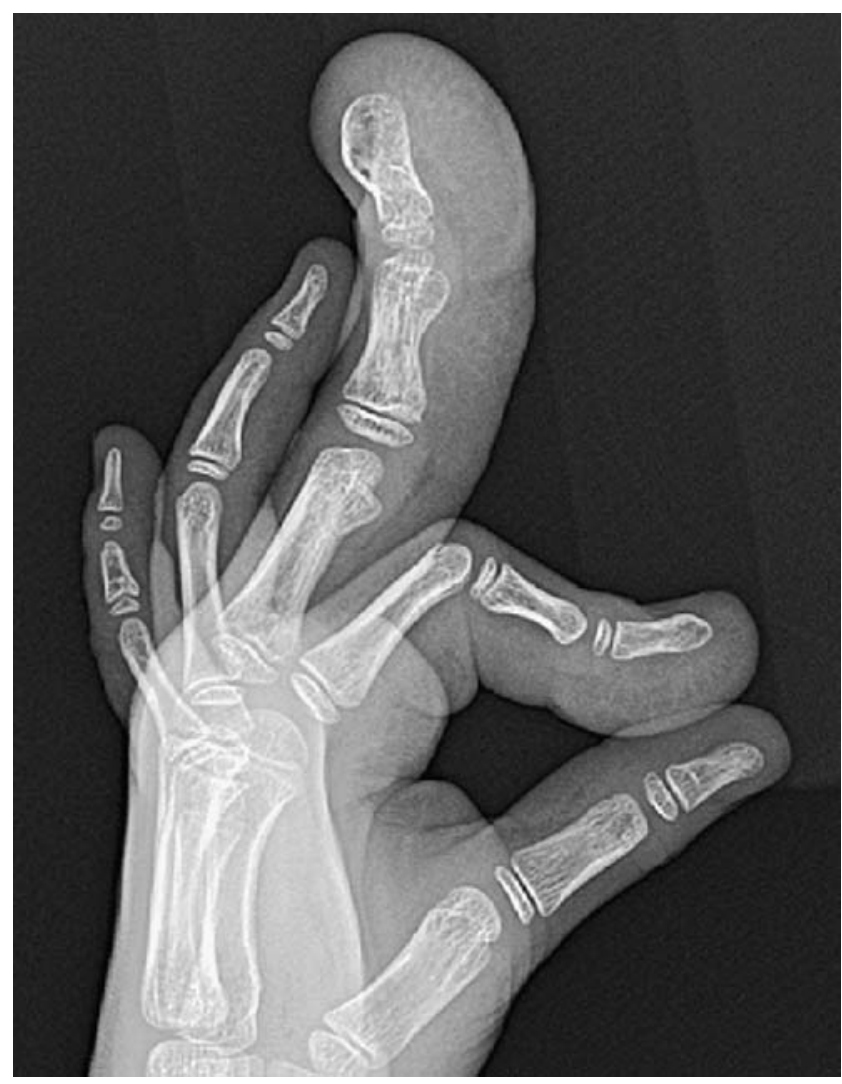

Fig. 2 Lateral radiograph, left hand

pose tissue overgrowth $[1,2]$. This condition affects either the hand or foot, classically occurring in a median or plantar nerve distribution [1,2]. Distal and volar digital involvement is typical (as in our case), and affected digit growth usually ceases after puberty [1]. Although the radiographic findings of this condition are generally pathognomonic and further evaluation with MRI is usually not necessary, macrodactyly can be due to numerous other causes, including Proteus syndrome, neurofibromatosis, and a variety of vascular lesions $[1,2]$.

\section{References}

1. Goldman AB, Kaye JJ (1977) Macrodystrophia lipomatosa: radiographic diagnosis. AJR 128:101-105

2. Fritz TR, Swischuk LE (2007) Macrodystrophia lipomatosa extending into the upper abdomen. Pediatr Radiol 37:1275-1277 